\title{
Accuracy of a questionnaire for identifying respiratory allergies in epidemiological studies*
}

\author{
Rosetta Pedotti', Laura Losappio², Mariangela Farinotti ${ }^{3}$, Donatella Preziosi², $\quad$ Rhinology 53: 49-53, 2015 \\ Irene Tramacere ${ }^{3}$, Chrysi Stafylaraki², Ambra Mascheri², Graziella Filippini³, \\ DOI:10.4193/Rhino 14.057 \\ Elide A. Pastorello² \\ ' Neuroimmunology and Neuromuscular Disorders Unit, Foundation IRCCS Neurological Institute C. Besta, Milan, Italy \\ *Received for publication: \\ February 25, 2014 \\ 2 Department of Allergology and Immunology, Niguarda Ca' Granda Hospital, Milan, Italy \\ Accepted: July 25, 2014
}

${ }^{3}$ Neuroepidemiology Unit, Foundation IRCCS Neurological Institute C. Besta, Milan, Italy

\begin{abstract}
Background: The assessment of allergic asthma (AA) and allergic rhinitis (AR) in epidemiological studies is often challenging. We performed a cross-sectional study to test the accuracy of a Questionnaire aimed at Identifying subjects with Respiratory Allergy (QIRA) in a simple and fast way.
\end{abstract}

Methods: One hundred-thirty subjects, 18-76 years of age, admitted consecutively at the Allergy Center of the Niguarda Ca' Granda Hospital of Milan were included. The questionnaire (index test) investigated the presence of AA and AR with seven questions enquiring history of symptoms, diagnosis made by a doctor, allergy tests performed, and treatments. After completing the questionnaire, all subjects were subsequently diagnosed by an allergist (reference standard).

Results: The accuracy of the questionnaire for the diagnosis of AA and AR was high (sensitivity $94.7 \%$ [95\% confidence interval Cl: 74.0-99.9] and specificity $99.1 \%$ [95\% Cl 95.1-100.0] for AA; sensitivity $82.8 \%$ [95\% Cl 71.3-91.1] and specificity $98.5 \%$ [95\% Cl 91.8-100.0] for AR).

Conclusion: The questionnaire significantly distinguished subjects with respiratory allergy from those without. The QIRA represents a valid and accurate tool for classifying subjects as having or not AA and/or AR in epidemiological studies.

Key words: allergic asthma, allergic rhinitis, diagnosis, epidemiology, questionnaire

\section{Introduction}

Allergic rhinitis (AR) and allergic asthma (AA) are common disorders affecting $5-40 \%$ of the general population. Typically, these disorders develop in atopic individuals. During the last two decades, several studies have been conducted to assess the prevalence of AR and AA in the general population (1). Moreover, the prevalence of respiratory allergies have been investigated also in relation with autoimmune diseases, such as diabetes and multiple sclerosis ${ }^{(2,3)}$ or with cancer ${ }^{(4)}$, with the aim of identifying potential associations between allergies and those disorders. Because of the difficulty in obtaining a specialized diagnosis by an allergist in large population studies, the presence of respiratory allergies was assessed in these studies by means of questionnaires investigating the history of allergies. Among those, the questionnaires used in children in the International Survey of Asthma and Allergies in Childhood (ISAAC) study ${ }^{(5)}$ and of the European Community Respiratory Health Survey (ECRHS) study ${ }^{(6)}$ are considered the most reliable and have been most frequently used. These questionnaires, as well as their subsequent modifications and revisions, relied on symptoms of $A R$ 
and AA (self-reported AR and AA; ISAAC study core questionnaire) or on reported doctor-diagnosed $A R$ and $A A$ (self-reported doctor-diagnosed AR and AA; ECRHS questionnaire). Depending on the study design, the questionnaires were self compiled ${ }^{(6)}$ or administered by direct interview ${ }^{(5)}$, or by phone interview ${ }^{(7)}$. These questionnaires have high sensitivity and can be useful to avoid underestimation of the prevalence of respiratory allergies particularly in population studies. However, in studies conducted in large populations, their administration may be very time consuming, because of the length of the questionnaire. We therefore developed a questionnaire aimed at identifying in a simple and fast way and by means of diagnosis-based questions, subjects with respiratory allergy in large population studies (QIRA, Questionnaire for Identifying Respiratory Allergies).

The aim of the present study was to evaluate the accuracy of the QIRA.

\section{Materials and methods}

A cross-sectional study was performed to assess the accuracy of the QIRA questionnaire investigating the medical history of $A A$ and AR. The study was approved by the Ethical Committee of the Niguarda Ca' Granda Hospital of Milan. One hundred-thirty subjects 18 to 76 years of age, including 90 subjects consecutively admitted for the first time at the Allergy Center of the Niguarda Ca' Granda Hospital and 40 accompanying relatives or friends, were included in the study. All subjects were recruited
Table 1. QIRA diagnostic criteria.

\begin{tabular}{ll}
\multicolumn{1}{|c}{ QIRA diagnostic criteria } & $\begin{array}{l}\text { Allergist's diagnostic criteria } \\
\text { (reference standard) }\end{array}$ \\
\hline $\begin{array}{l}\text { Positive symptoms } \\
\text { and }\end{array}$ & $\begin{array}{l}\text { Positive symptoms } \\
\text { and }\end{array}$ \\
$\begin{array}{l}\text { Positive reported doctor-diag- } \\
\text { nosis }\end{array}$ & $\begin{array}{l}\text { Positive diagnostic tests for respi- } \\
\text { and }\end{array}$ \\
$\begin{array}{l}\text { ratory allergy } \\
\text { Positive tests for respiratory }\end{array}$ & \\
allergy
\end{tabular}

between October 2012 and December 2012. A written informed consent was obtained by all participating subjects. A questionnaire investigating the medical history of respiratory allergies was administered to all subjects by a trained interviewer. The QIRA questionnaire (Figure 1) was a revised version of that used by us in a previous epidemiological study ${ }^{(2)}$, and was based on the core questions of the ECRHS questionnaire partially modified by Verlato et al. ${ }^{\left({ }^{8}\right)}$. The first item of the questionnaire enquired the occurrence of symptoms typical of $A A$ or $A R$ including hay fever. If a positive response was given, six other questions were administered enquiring about presence of doctor-diagnosed allergic AA and/or AR; allergic tests performed, including skin prick tests (SPTs), radioallergosorbent tests (RASTs) and respiratory tests; first and most recent occurrence of the allergic condition; and what if any treatment was taken. Sub-

\begin{tabular}{|c|c|c|c|c|c|c|c|c|}
\hline & & & $\begin{array}{l}\text { 2. Did a doctor } \\
\text { diagnosed... }\end{array}$ & $\begin{array}{l}\text { 3. Have you had } \\
\text { any clinical or } \\
\text { laboratory tests } \\
\text { because of this } \\
\text { disease? } \\
\end{array}$ & $\begin{array}{l}\text { 4. Which tests did you take } \\
\text { for this disease? }\end{array}$ & $\begin{array}{l}\text { 5. How old were } \\
\text { you when you } \\
\text { had the first } \\
\text { episode? }\end{array}$ & $\begin{array}{l}\text { 6. How old were } \\
\text { you when you } \\
\text { had the most } \\
\text { recent episode? }\end{array}$ & \begin{tabular}{|l|} 
7. Have you ever taken \\
drug/s or any other \\
treatment for this disease?
\end{tabular} \\
\hline Q1 & $\begin{array}{l}\text { Have you ever had } \\
\text { sneezing, or a runny } \\
\text { or a blocked nose } \\
\text { upon exposure to } \\
\text { animals, pollen, } \\
\text { dust, or chemicals, } \\
\text { when you did not } \\
\text { have a cold or the } \\
\text { flu? } \\
\text { (If YES, specify } \\
\text { exposure) } \\
\end{array}$ & $\begin{array}{l}\text { YES } \square \_\mid \\
\text {NO } \square \text { (go to Q2) }\end{array}$ & $\begin{array}{c}\text { Allergic rhinitis } \\
\text { including hay } \\
\text { fever? }\end{array}$ & $\begin{array}{l}\text { YES } \square \leq \text { (go to 5) } \\
\text { NO } \square \text { ( }\end{array}$ & $\begin{array}{l}\text { A) Skin prick tests? } \\
\text { Were they } \\
\text { normal? } \\
\text { B) Blood tests? } \\
\begin{array}{l}\text { Were they } \\
\text { normal? }\end{array}\end{array}$ & $\frac{\mid}{\text { years }} \mid$ & $\frac{\mathrm{L}}{\mathrm{L} \text { yers }} \mid$ & $\frac{\text { YES L_ }}{\text { Which ones? }}$ \\
\hline Q2 & $\begin{array}{l}\text { Have you ever had } \\
\text { troubles in breathing } \\
\text { (with coughing, } \\
\text { wheezing or } \\
\text { whistling, feeling of } \\
\text { tightness in your } \\
\text { chest, shortness of } \\
\text { breath) upon } \\
\text { exposure to animals, } \\
\text { pollen, dust, } \\
\text { moulds, or } \\
\text { chemicals, when } \\
\text { you did not have a } \\
\text { cold or the flu? } \\
\\
\text { (If YES, specify } \\
\text { exposure) }\end{array}$ & $\begin{array}{l}\text { YES }\left|\_\right| \\
\text {NO } \square \text { (STOP) }\end{array}$ & $\begin{array}{l}\text { Allergic asthma? } \\
\text { YES } \\
\text { NO }\end{array}$ & $\begin{array}{l}\text { YES } \\
\text { NO } \square \text { (go to 5) }\end{array}$ & $\begin{array}{l}\text { A) Skin prick tests? } \\
\text { Were they } \\
\text { normal? } \\
\text { B) Blood tests? } \\
\text { Were they } \\
\text { normal? } \\
\begin{array}{l}\text { C) Breathing tests in a } \\
\text { laboratory specialized for } \\
\text { lung function measurement? } \\
\text { Were they } \\
\text { normal? }\end{array}\end{array}$ & $\frac{\mid}{\text { years }} \mid$ & $\frac{\mid}{\text { years }} \mid$ & $\mid \begin{array}{l}\text { YES } \mid \_ \text {Which ones? } \\
\begin{array}{c}\text { (inhalers, tablets, } \\
\text { vaccination) }\end{array}\end{array}$ \\
\hline
\end{tabular}

Figure 1. The QIRA questionnaire for the identification of subjects with allergic asthma and allergic rhinitis. 


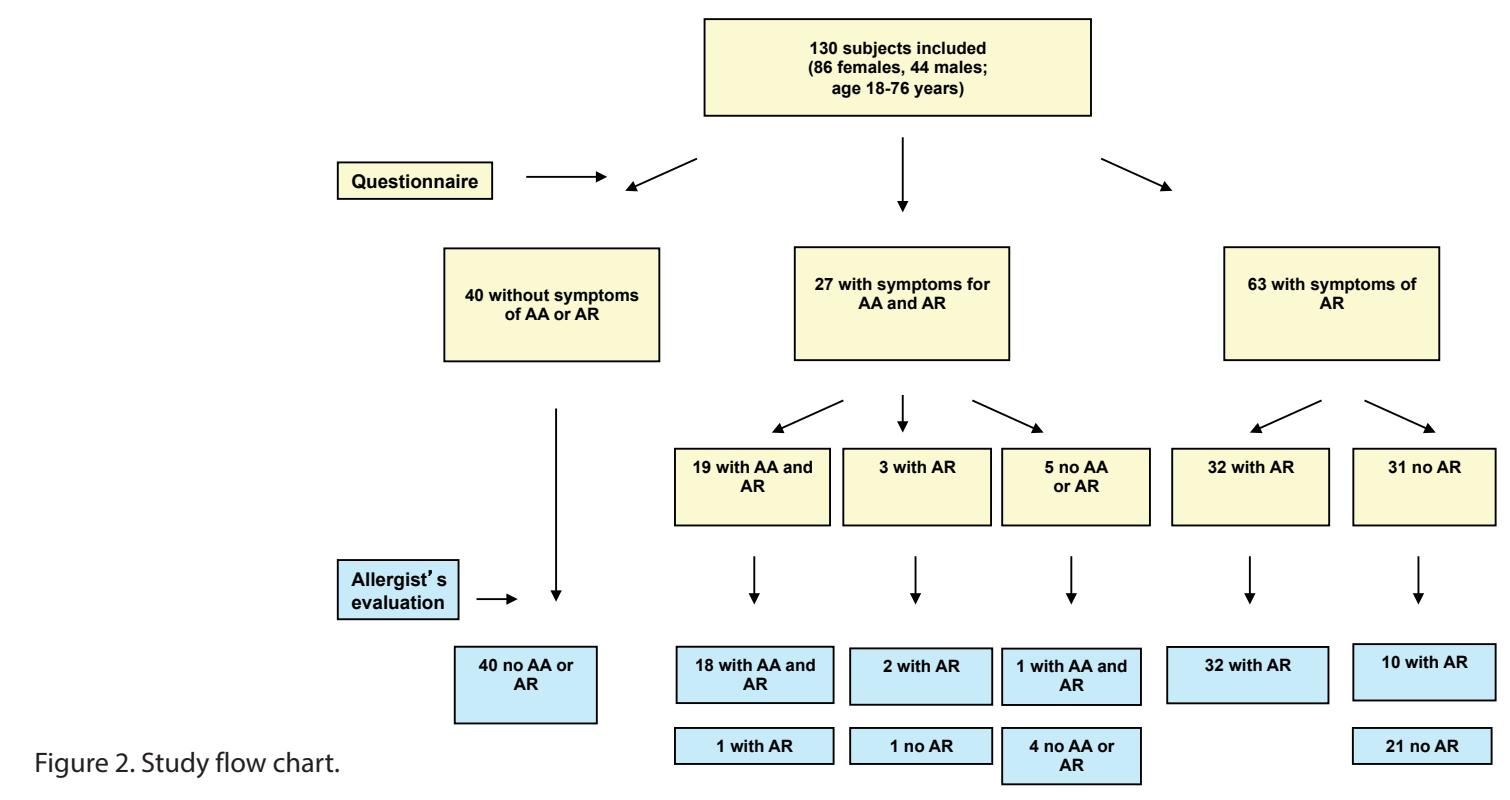

Table 2. ARIA and GINA diagnostic criteria.

\section{A: ARIA criteria for the diagnosis of allergic rhinitis}

Allergic rhinitis can be diagnosed in the presence of:

1. the three cardinal symptoms of sneezing, nasal obstruction and rhinorrhea;

2. coordination between a typical history of allergic symptoms and diagnostic tests, in vivo or in vitro, for the demonstration of allergen specific IgE antibodies

B: GINA criteria for the diagnosis of allergic asthma in SPT positive patients

Allergic asthma can be diagnosed in the presence of:

1. characteristic symptoms of episodic breathlessness, wheezing, cough and chest tightness, plus

2. demonstration of reversibility with an improvement in FEV1 of at least $12 \%$ post bronchodilator and/or

3. measurements of airway responsiveness to methacholine in patients with symptoms consistent of asthma

FEV1: forced expiratory volume in one second.

jects were classified as having $A A$ and/or AR if giving a positive answer respectively to the questions "Did a doctor diagnosed allergic asthma" and/or "Did a doctor diagnosed allergic rhinitis including hay fever", and if reporting positivity to allergy tests (QIRA diagnostic criteria) (Table 1).

After responding to the questionnaire, all subjects were examined by an allergist who was masked to the QIRA and performed SPTs with a standard panel of the most significant seasonal (Birch, Hazel, Olive, Grass, Ragweed, Artemisia and Parietaria pollens and Cladosporium and Alternaria moulds) and perennial aeroallergens (Dermatophagoides pteronyssinus and farinae, dog and cat), and respiratory tests (Baseline spirometry; Bronchodilation test and/or Methacholine Challenge test if necessary). The diagnosis of $A A$ and/or AR was then performed by the allergist according to the well established GINA criteria for asthma in SPT positive patients ${ }^{\left({ }^{9}\right)}$ and the ARIA criteria for $A R^{(10)}$. Table $2 A$ and $2 B$ show respectively ARIA and GINA diagnostic criteria. On this basis, diagnosis of AA and AR made by the allergist was used as the reference standard to assess the accuracy of the questionnaire in discriminating between individuals with respiratory allergy and those without (Table 1). The accuracy was evaluated by means of the following statistical measures: i) sensitivity, that is the proportion of individuals with AA and/or AR diagnosed by the allergist that were classified from the questionnaire as having $A A$ and/or AR (i.e. correctly classified from the questionnaire); ii) specificity, that is the proportion of individuals without $A A$ and/or AR diagnosed by the allergist that were classified from the questionnaire as not having $A A$ and/or $A R$; iii) positive predictive values (PPV), that is the probability of having AA and/ or AR given the positive results of the questionnaire; iv) negative predictive values (NPV), that is the probability of not having AA and/or AR given the negative results of the questionnaire.

\section{Statistical analysis}

Statistical analyses were performed using SAS Version 9.3 (SAS Institute Inc. Cary, NC, USA).

\section{Results}

Figure 2 depicts the study flow chart. A total of 130 subjects ( 86 females and 44 males, age of 18-76 years) were included. The mean interview length of the QIRA questionnaire was 3 minutes (median 2.8; range 2.0-8.5). Twenty-seven subjects reported at 
Table 3A and B. Accuracy of the QIRA questions on allergic asthma and allergic rhinitis in relation to allergist's diagnosis.

\section{A) Allergic Asthma}

\begin{tabular}{|c|c|c|c|c|c|c|c|c|}
\hline Diagnosis & TP & FN & TN & FP & $\begin{array}{c}\text { Sensitivity } \\
(95 \% \mathrm{CI})\end{array}$ & $\begin{array}{c}\text { Specificity } \\
(95 \% \text { CI) }\end{array}$ & PPV & NPV \\
\hline Complete QIRA & 18 & 1 & 110 & 1 & 94.7 (74.0-99.9) & $99.1(95.1-100.0)$ & 94.7 & 99.1 \\
\hline Symptoms only & 19 & 0 & 103 & 8 & $100.0(85.4-100.0)$ & $92.8(86.3-96.8)$ & 70.4 & 100.0 \\
\hline \multicolumn{9}{|l|}{ B) Allergic Rhinitis } \\
\hline Diagnosis & TP & FN & TN & $\mathbf{F P}$ & $\begin{array}{c}\text { Sensitivity } \\
(95 \% \mathrm{CI})\end{array}$ & $\begin{array}{c}\text { Specificity } \\
(95 \% \mathrm{CI})\end{array}$ & PPV & NPV \\
\hline Complete QIRA & 53 & 11 & 65 & 1 & $82.8(71.3-91.1)$ & $98.5(91.8-100.0)$ & 98.1 & 85.5 \\
\hline Symptoms only & 63 & 1 & 39 & 27 & $98.4(91.6-100.0)$ & $59.1(46.3-71.1)$ & 70.0 & 97.5 \\
\hline
\end{tabular}

$\mathrm{TP}=$ true positive; $\mathrm{FN}=$ false negative; $\mathrm{TN}=$ true negative; $\mathrm{FP}=$ false positive. Data for sensitivity and specificity are presented as percentages. $\mathrm{PPV}=$ Positive predictive value; NPV = negative predictive value.

the interview symptoms for $A A$ and $A R, 63$ symptoms of $A R$, and 40 subjects reported no symptoms of AA or AR. Nineteen subjects were classified from QIRA as having both $A A$ and $A R$, and 35 as having AR.

The accuracy of the QIRA questionnaire as compared with allergist's diagnosis of AA and AR, together with the $95 \%$ confidence interval $(\mathrm{Cl})$, are reported in Table $3 \mathrm{~A}$ and $3 \mathrm{~B}$. Out of 19 patients classified by the questionnaire to have $A A, 18$ were diagnosed by the allergist to have $A A$, and 1 tested negative. Of the 111 patients who were deemed to not have AA on the questionnaire, 1 tested positive for AA (sensitivity $94.7 \%$ [95\% Cl 74.0-99.9]; specificity 99.1\% [95\% Cl 95.1-100.0]; PPV 94.7\% NPV 99.1\%). AR was diagnosed by the allergist in 64 subjects, of which 53 were classified by the QIRA questionnaire as having it, and was not diagnosed in 66 subjects, of which 65 were classified by QIRA as not having it (sensitivity $82.8 \%$ [95\% CI 71.3-91.1]; specificity 98.5\%, [95\% CI 98.1-100.0]; PPV 98.1\% NPV 85.5\%). All of the subjects that were classified by the QIRA questionnaire as not having $A R$ but that received the diagnosis by the allergist (false negatives, $\mathrm{n}=11$ ) reported symptoms of $\mathrm{AR}$ at the $\mathrm{QIRA}$, but either have never seen a doctor for these symptoms, or have seen a doctor but had never perform allergy tests. Thus, in these 11 subjects the diagnosis of AR made by the allergist at the time of the study was a new diagnosis.

The sensitivity of the QIRA question on the presence of symptoms of AA was higher than that of the complete QIRA, which required positivity to symptoms, doctor-diagnosis of $A A$ and allergy tests (100.0\% versus $94.7 \%$ ). However, specificity
(92.8\%) and PPV (70.4\%) of the question on symptoms of AA were lower compared with those of the QIRA $(99.1 \%$ for specificity and $94.7 \%$ for PPV). Concerning AR, the sensitivity of the question on the presence of symptoms was higher than that of the complete QIRA ( $98.4 \%$ versus $82.8 \%$ ), but specificity $(59.1 \%)$ and PPV (70.0\%) were importantly lower.

\section{Discussion}

This study showed that the QIRA questionnaire for respiratory allergy detected with a good accuracy subjects who suffered $A A$ and/or AR. Moreover, QIRA was administered through an interview of an average length of three minutes, and thus represents an advantage over other questionnaires for respiratory allergies that require longer time to be administered.

The criteria to be classified by QIRA as having AA and/or AR were to have provided a positive answer to the questions about having symptoms, having or not a doctor-diagnosis of AA and/or $A R$, and having positive allergic tests. This was decided because positivity to allergy tests is generally required to diagnose $A A$ or $A R^{(9)}$. In our population, all subjects reporting a doctor-diagnosis of AA and/or AR reported also positivity to allergy tests. Using these criteria, QIRA was found to classify with high sensitivity and specificity subjects with AA and AR.

We observed that the sensitivity of the question on symptoms of AA and AR was higher than that of the complete QIRA. However, the specificity of these questions and their PPV were importantly lower than those of the complete QIRA. These data confirm previous studies showing that the questions on doctordiagnosis are the most reliable item to correctly classify subjects 
with specific diseases among positive questionnaire respondents ${ }^{(7,11)}$. In this regard, the QIRA questionnaire represents an advantage over questionnaires relying only on symptomsbased questions ${ }^{(5)}$. Indeed, compared with the specificity for $A R$ reported by means of a quantitative score for allergic rhinitis (SFAR) of the study by Annesi-Maesano and colleagues ${ }^{(12)}$, the specificity of the complete QIRA for AR was higher ( $99.1 \%$ in our study versus $83 \%$ in the study of Annesi-Maesano et al.). This is likely to be related to the fact that compared to the SFAR, the QIRA questionnaire relied on the presence of doctor-diagnosed AR. Another interesting aspect of our study is that the validation of the QIRA questionnaire was performed using an integrated approach of diagnostic methods for the diagnosis of both $A A$ and AR. This approach allowed to diagnose AA in $30 \%$ of the subjects affected by AR. Compared with other questionnaires investigating separately AA or AR, our questionnaire gives the opportunity to consider simultaneously the presence of $A A$ and AR as different aspects of the same disease. This might be particularly useful in epidemiological studies aimed at identifying the association of respiratory atopic allergy with other diseases, such as autoimmune diseases and cancer ${ }^{(2-4)}$.

One limitation of this work is that the study setting was at an Allergy Hospital Center. Compared to the general population, the high prevalence of AA and AR observed in our setting might have caused an overestimation of the predictive values and probably of the accuracy of the test ${ }^{(13)}$. Therefore, this is a pilot study that requires further validation in a larger, more general population.

In conclusion, the proposed QIRA questionnaire for AA and AR may represent a useful tool to identify respiratory allergy in large population studies.

\section{Acknowlegdement}

This study was supported in part by Italian Ministry of Health -Progetto Strategico 2007 (to RP and GF) and by Italian Ministry of Health - Progetto Giovani Ricercatori GR-2009-1607206 (to $\mathrm{RP})$.

\section{Authorship contribution}

RP: Conceived the study, analyzed results and wrote the paper; LL: Conducted the work with patients, analyzed the results, contributed to write the paper; MF: Discussed study design, analyzed results and discussed the paper; DP: Conducted the work with patients; IT: Discussed study design, analyzed results, performed the statistical analysis; CS: Conducted the work with patients; AM: Conducted the work with patients; GF: Conceived the study, analyzed results and wrote the paper; EAP: Conceived the study, supervised the work and wrote the paper

\section{Conflicts of Interest}

None

\section{References}

1. Johansson SG, Hourihane JO, Bousquet J, Bruijnzeel-Koomen C, Dreborg S, Haahtela T et al. A revised nomenclature for allergy. An EAACI position statement from the EAAC nomenclature task force. Allergy. 2001; 56: 813-824.

2. Pedotti R, Farinotti M, Falcone C, Borgonovo L, Confalonieri P, Campanella A et al. Allergy and multiple sclerosis: A population-based case-control study. Mult Scler. 2009; 15: 899-906.

3. Tosca MA, Silvestri M, Olcese R, D'Annunzio G, Pistorio A, Lorini R, et al. Allergic sensitization and symptoms, body mass index, and respiratory function in children with type 1 diabetes mellitus. Ann Allergy Asthma Immunol. 2012; 108: 128-129.

4. Merrill RM, Isakson RT, Beck RE. The association between allergies and cancer: What is currently known? Ann Allergy Asthma Immunol. 2007; 99: 102-116.

5. Asher MI, Keil U, Anderson HR, Beasley R, Crane J, Martinez F, et al. International study of asthma and allergies in childhood (ISAAC): Rationale and methods. Eur Respir J. 1995; 8: 483-491.

6. Burney PG, Luczynska C, Chinn S, Jarvis
D. The European community respiratory health survey. Eur Respir J. 1994; 7: 954-960.

7. Soller L, Ben-Shoshan M, Harrington DW, Fragapane J, Joseph L, St Pierre $Y$ et al. Overall prevalence of self- reported food allergy in Canada. J Allergy Clin Immunol. 2012; 130: 986-998.

8. Verlato G, Corsico A, Villani S, Cerveri I, Migliore E, Accordini S, et al. Is the prevalence of adult asthma and allergic rhinitis still increasing? Results of an italian study. J Allergy Clin Immunol. 2003; 111: 1232-1238.

9. Bateman ED, Hurd SS, Barnes PJ, Bousquet J, Drazen JM, FitzGerald M, et al. Global strategy for asthma management and prevention: Gina executive summary. Eur Respir J. 2008; 31: 143-178.

10. Bousquet J, Van Cauwenberge $P$, Khaltaev N Allergic rhinitis and its impact on asthma. J Allergy Clin Immunol. 2001; 108: 47-33.

11. Kilpelainen M, Terho EO, Helenius $H$, Koskenvuo M. Validation of a new questionnaire on asthma, allergic rhinitis, and conjunctivitis in young adults. Allergy. 2001; 56: 377-384.

12. Annesi-Maesano I, Didier A, Klossek M Chanal I, Moreau D, Bousquet J. The score for allergic rhinitis (sfar): A simple and valid assessment method in population studies. Allergy. 2002; 57: 107-114.

13. Leeflang MM, Bossuyt PM, Irwig L. Diagnostic test accuracy may vary with prevalence: Implications for evidencebased diagnosis. J Clin Epidemiol. 2009; 62: 5-12.

Elide Anna Pastorello Unit of Allergy and Immunology Niguarda Ca' Granda Hospital Piazza Ospedale Maggiore 3 Milan 20162 Italy

Tel: +390264442751

Fax: +390264442082

E-mail: elide.pastorello@ospedaleniguarda.it 